\title{
INCORPORATION OF VITAMIN E ONTO CROSS-LINKED GALACTOMANNAN PHOSPHATE MATRIX AND IN VITRO STUDY
}

\author{
JULIATI BR TARIGAN ${ }^{1 *}$, DJENDAKITA PURBA ${ }^{2}$, CUT FATIMAH ZUHRA ${ }^{3}$ \\ ${ }^{1}$ Department of Chemistry, University Of Sumatera Utara, Medan, Indonesia. ${ }^{2}$ Department of Pharmacy, University of Sumatera Utara, \\ Medan, Indonesia. Email: juliati@usu.ac.id
}

Received: 06 January 2018, Revised and Accepted: 13 February 2018

\section{ABSTRACT}

Objective: This study demonstrated the incorporation of Vitamin E from palm fatty acid distillate onto crosslinked galactomannan phosphate (CGP) matrix.

Methods: CGP was obtained from the crosslinking reaction of galactomannan from Arenga pinnata (GAP) with tri-sodium metaphosphate (TMF) ranging from 1:1 to 4:3 while incorporation of Vitamin E was conducted in two steps to form films. The reliability study of Vitamin E in CGPVE was conducted using a solution of pepsin and sodium chloride and also in solution of pancreatin and buffer phosphate.

Results: The Fourier-transform infrared spectrum indicated the presence of phosphate in CGP while the scanning electron microscope images depicted the changes of surface morphology from smooth (GAP) to rough and hollow (CGP) which confirmed that crosslink had occurred. The swelling study of CGP showed that the swelling indexes were similar and decreased with the increase of TMF. The efficiency of CGP to absorb Vitamin E ranged from $89.66 \%$ to $91.09 \%$. The in vitro releasing study of Vitamin E in simulated gastric fluid and simulated intestinal fluid showed that only a small amount of Vitamin E was released.

Conclusions: This study demonstrated that CGP can be prepared and is potentially useful for drug delivery to the colon.

Keywords: Galactomannan, Arenga pinnata, Palm fatty acid distillate, Vitamin E.

(C) 2018 The Authors. Published by Innovare Academic Sciences Pvt Ltd. This is an open access article under the CC BY license (http://creativecommons. org/licenses/by/4. 0/) DOI: http://dx.doi.org/10.22159/ajpcr.2018.v11i5.24645

\section{INTRODUCTION}

Colon cancer has been identified as the second highest cause of death in the United States and the sixth in Indonesia. A high intake of antioxidants may decrease the risk of colon cancer and prevent the metastases [1-3]. One of the antioxidant sources naturally abundant is tocopherol and tocotrienol or Vitamin E which is soluble in water [4]. However, Vitamin E degrades easily by chemical or physical action during storage or when it is delivered to the appropriate site of action after ingestion [5]. Therefore, encapsulation or incorporation methods have been developed to protect Vitamin E from degradation. Several ways were used to incorporate Vitamin E onto matrix hydrocolloid or non-hydrocolloid: On hydrocolloid matrix, for example, onto polyvinylpyrrolidone in supercritical condition [6], or in chitosan hydrocolloid matrix [7]. Other compounds such as gliadin, calciumalginate, calcium pectinate, and a mixture of wheat and chitosan have been identified as suitable for protecting Vitamin E [5]. However, all the encapsulated material remains degraded due to acid and enzyme in the intestine. Therefore, modification in a hydrocolloid matrix should be done to protect the active material from degradation in the stomach and small intestine and released in the colon.

Given the fact that modified polysaccharide has more stability against enzyme than its natural form, more attention has been paid, particularly to a cross-linked polysaccharide which is known to have a lower swelling property than its natural form [8,9]. Gliko-Kabir et al. showed that the swelling property of guar gum was reduced significantly after being cross-linked with glutaraldehyde [10]. In our previous research, galactomannan, which was cross-linked with trisodium tri-metaphosphate, showed a decrease of swelling property at $87 \%$ in distillate water and the particle size also became smaller [11]. Galactomannan used in that study was extracted from Arenga pinnata (kolang-kaling) which is abundant in Indonesia [12]. Galactomannan is a water-soluble polysaccharide [13] containing galactose and mannose in the range of $1: 1.33$ and having $\mathrm{IC}_{50}=22,109 \mathrm{mg} / \mathrm{mL}$ [14]. In the present work, the incorporation of Vitamin $\mathrm{E}$ from palm fatty acid distillate (PFAD) onto crosslinked galactomannan phosphate (CGP) matrix to form cross-linked galactomannan phosphate Vitamin E (CGPVE) was demonstrated. The preparation of CGP was conducted with various concentrations of phosphate and galactomannan, using the drop by drop method. The swelling property of CGP was determined in distillate water, simulated gastric fluid (SGF), simulated intestinal fluid (SIF), and also in vitro.

\section{MATERIALS AND METHODS}

\section{Materials}

A. pinnata seed was obtained from a local market in Medan, North Sumatera, Indonesia, without separating for the degree of hardness. All chemicals used in this experiment were obtained from Sigma-Aldrich and were used without further purification. PFAD was obtained from Oleochemical Industry in Medan, and the concentration of Vitamin E in PFAD was $70 \%$.

The trace metal element contained in galactomannan from A. pinnata (GAP) was determined according to the AOCS 993-14 method using Perkin Elmer Nexion $\times 300$ inductively coupled plasmamass spectrophotometry. The surface image of GAP was obtained using a scanning electron microscope (SEM) JEOL JSM-6360LA while the changes of the functional group of all samples were measured using Fourier transform infrared (FT-IR) Perkin Elmer. The concentration of Vitamin E was analyzed using the AOCS Ce8-89 method in high-performance liquid chromatography (HPLC) while the spectrophotometer ultraviolet (UV)-visible Shimadzu 1800 was used to determine released and trapped Vitamin $\mathrm{E}$ in the matrix. 


\section{METHODS}

\section{Extraction of GAP seed}

Extraction of GAP was conducted in neutral conditions based on the method used in our previous research with a slight modification [11]. $20 \mathrm{~g}$ of $A$. pinnata seed which was already cut into $2 \mathrm{~cm}$ size was added to $150 \mathrm{~mL}$ distillate water and was crushed mechanically in a blender for $5 \mathrm{~min}$ and stored in a cold room for $24 \mathrm{~h}$. Next, the blended seed was centrifuged at $9500 \mathrm{rpm}$ for $15 \mathrm{~min}$ to obtain supernatant 1 . The residue 1 was added next with $75 \mathrm{~mL}$ of water followed with blender and centrifuge in similar conditions to obtain supernatant 2 . The supernatant 1 and 2 were mixed together and added with $96 \%$ ethanol in the range of 1:2 and stored in a cold room. After $24 \mathrm{~h}$ storage, the precipitate was separated using a filter bag, and the residue was soaked in $100 \mathrm{~mL}$ ethanol $96 \%$ for $24 \mathrm{~h}$, followed by separating and soaking again in $100 \mathrm{~mL}$ of ethanol for the next $24 \mathrm{~h}$. The residue obtained after separation was dried in a desiccator.

\section{Preparation of cross-linked galactomannan phosphate (CGP)}

CGP was prepared following the procedure from the previous research with slight modification $[11,15]$. $1 \mathrm{~g}$ of GAP powder was dissolved in $80 \mathrm{~mL}$ of distillate water and added by $2 \mathrm{M} \mathrm{NaOH}$ solution until $\mathrm{pH} 12$ and the GAP had swelled. In another place, $1 \mathrm{~g}$ of TMP was dissolved in $20 \mathrm{~mL}$ deionized water and was added drop by drop with GAP solution under stirring at $1000 \mathrm{rpm}$ and room temperature for $2 \mathrm{~h}$ (the range of GAP: TMP used was 1: 1, CGP1). The $\mathrm{pH}$ of the CGP solution was kept at 12 by adding $2 \mathrm{M} \mathrm{NaOH}$. The CGP solution then was spread on $13 \mathrm{~cm} \times$ $13 \mathrm{~cm}^{2}$ glass plates and was evaporated in oven blower at $45^{\circ} \mathrm{C}$ for $18 \mathrm{~h}$. The dry film was washed with distillate water until $\mathrm{pH}$ neutral and dried again in the oven. The dried films were stored in a closed box for FT-IR and SEM analysis. The swelling property was determined in distillate water, SGF and SIF solution and was done triplicate. The same procedure also conducted for CGP 2 (1: 2), CGP 3 (1: 3), CGP 4 (1: 4), CGP 5 (2: 1), CGP 6 (2: 3), CGP 7 (4:1), CGP 8 (3: 1), CGP 9 (3: 2), and CGP 10 (4:3).

\section{Incorporation of Vitamin E from PFAD onto CGP solution}

Incorporation of Vitamin E from PFAD onto CGP matrix was conducted based on a previous research method $[7,15]$. The incorporation of Vitamin E into CGP matrix was prepared in two steps. First, $20 \mathrm{~mL}$ of ethanol was added to $0.5 \mathrm{~g}$ of PFAD and $0.5 \mathrm{~g}$ tween 80 and was stirred in the darkroom for $30 \mathrm{~min}$. Second, the solution was added by matrix CGP drop by drop and stirred for $2 \mathrm{~h}$. The incorporation solution was poured in a glass plate (length $13 \mathrm{~cm}$, height $7 \mathrm{~cm}$, and width $3 \mathrm{~cm}$ ) and was evaporated in the oven blower at $37^{\circ} \mathrm{C}$ for $24 \mathrm{~h}$. The film was washed with distillate water until $\mathrm{pH} 7$ and dried again for $5 \mathrm{~h}$. The dried film was stored in a closed container. The water which was used to wash the dried film was used to determine the unloaded Vitamin $\mathrm{E}$ using extraction with $50 \mathrm{~mL}$ hexane. Spectrophotometer UV-visible at a wavelength of $297 \mathrm{~nm}$ was used to determine the amount of Vitamin $\mathrm{E}$ trapped onto matrix CGP. All the CGPVE film formed was characterized using FT-IR, SEM and the releasing of Vitamin E in SIF and SGF with or without enzyme.

\section{In vitro study of CGPVE film}

The reliability study of Vitamin E in CGPVE was conducted using a solution of pepsin and sodium chloride and also in the solution of pancreatin and buffer phosphate following the procedure from previous researchers [16,17]. $150 \mathrm{mg}$ of CGPVE was added by $30 \mathrm{~mL}$ of SGF solution and $5 \mathrm{~mL}$ of tween 80 and stirred at $100 \mathrm{rpm}$ for $30 \mathrm{~min}$ at $37^{\circ} \mathrm{C}$. Next, the solution was extracted 2 times with $50 \mathrm{~mL}$ hexane. The concentration of Vitamin E in hexane was determined using UV-visible at a wavelength of $297 \mathrm{~nm}$. The swelled aggregate formed using the SGF solution was added to $30 \mathrm{~mL}$ of SIF and $5 \mathrm{~mL}$ tween 80 and stirred for 4 $\mathrm{h}$ at $37^{\circ} \mathrm{C}$. Next, the solution was extracted 2 times with $50 \mathrm{~mL}$ hexane, and the concentration of Vitamin $\mathrm{E}$ was determined using UV-visible.

\section{RESULTS AND DISCUSSION}

\section{The extraction of GAP}

The percentage of GAP obtained from extraction process was $4.5 \%$, which is similar to the result of our previous research [14]. However, in this study, the extraction procedure of GAP was slightly modified in that after the precipitation process with alcohol the precipitate was separated using a filter bag, while in the previous research centrifugation was applied for precipitation. The GAP found after extraction is a white powder that contains a small amount of metal. Cuprum and zinc were the main metals contained in GAP. Since only alcohol was used to precipitate GAP from the seed and without any further purification process necessary, GAP was considered to be edible and environmentally friendly [18]. Commonly, galactomannan from gum was used in the pharmaceutical and cosmetic industries [19].

\section{Efficiency of trapped Vitamin E PFAD in CGP}

The concentration of Vitamin E contained in PFAD was 70\%. The HPLC analysis showed that the component of Vitamin E was $\alpha$-tocopherol $20,97 \%$, tocotrienol $15,88 \%, \beta$ - tocotrienol $2,43 \%, \gamma$-tocotrienol 22,31 ; and $\delta$-tocotrienol $8,48 \%$, and squalene, triglyceride, diglyceride, monoglyceride, and fatty acid in trace amounts. Spectrophotometer UV-visible was used to determine the unloaded Vitamin E, and the result was used to calculate the concentration of trapped Vitamin E. Determination of entrapment efficiency Vitamin E (EE) onto matrix CGP was calculated based on the equation below $[5,6]$.

$$
\mathrm{EE}(\%)=\frac{\mathrm{V}-\mathrm{U}}{\mathrm{V}} \times 100
$$

Where:

$\mathrm{V}=$ total Vitamin $\mathrm{E}$ used

$\mathrm{U}=$ total unloaded Vitamin $\mathrm{E}$

Graph 1 presents the efficiency of Vitamin E for all the CGPVE. Highefficiency values were found for all the CGPVE in the range of 89.66$91.09 \%$ with the highest $\mathrm{E}$ found at CGP 3. These EE results showed that CGP has high ability to entrap Vitamin E PFAD, which was confirmed by SEM images in Fig. 1.

Based on Graphs 2 and 3 the percentage of released Vitamin E was governed by the concentrations of GAP and tri-sodium metaphosphate (TMF). The fact that only a small amount of Vitamin $\mathrm{E}$ was released in GI condition showed that matrix CGP has good stability as a drug carrier to the colon. Gliko-Kabir et al. demonstrated that cross-linked guar gum with TMF was easily degraded using enzyme and could retard release a drug with low solubility in water. Therefore, it was suggested that the matrix could be used as a drug carrier to the colon. A similar result was obtained when using glutaraldehyde as a crosslinking agent, and it was confirmed that the matrix was easy to degrade in the colon [10].

\section{FT-IR characterization}

The GAP, CGP, Vitamin E, and CGPVE were confirmed by FT-IR spectroscopy with absorbance spectrum recorded in the wavelength range from 4000 to $400 \mathrm{~cm}^{-1}$, as presented in Fig. 2. As can be seen, the entire spectrum showed a peak at $3500 \mathrm{~cm}^{-1}$, which represents the $-\mathrm{OH}$ stretching group. However, the $-\mathrm{OH}$ peak at CGP (Fig. 1b) was slightly different due to some of the $-\mathrm{OH}$ groups having been cross-linked

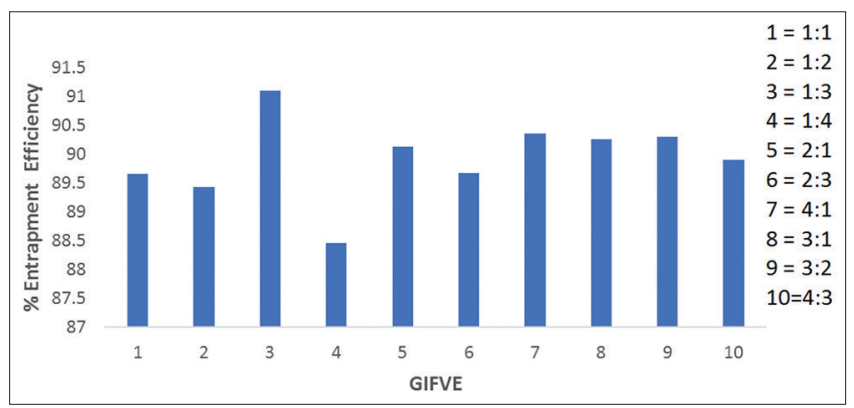

Graph 1: Entrapment efficiency of Vitamin E palm fatty acid distillate onto matrix CGP 


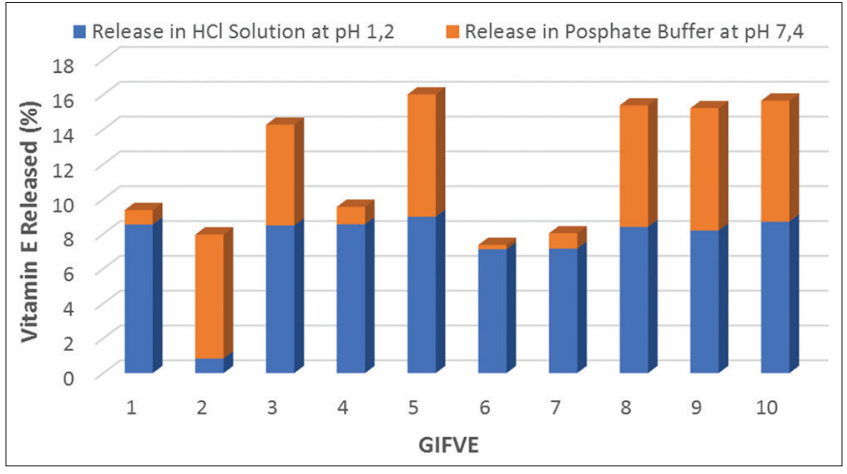

Graph 2: Released profile of Vitamin E in $\mathrm{HCl}$ solution and phosphate buffer condition

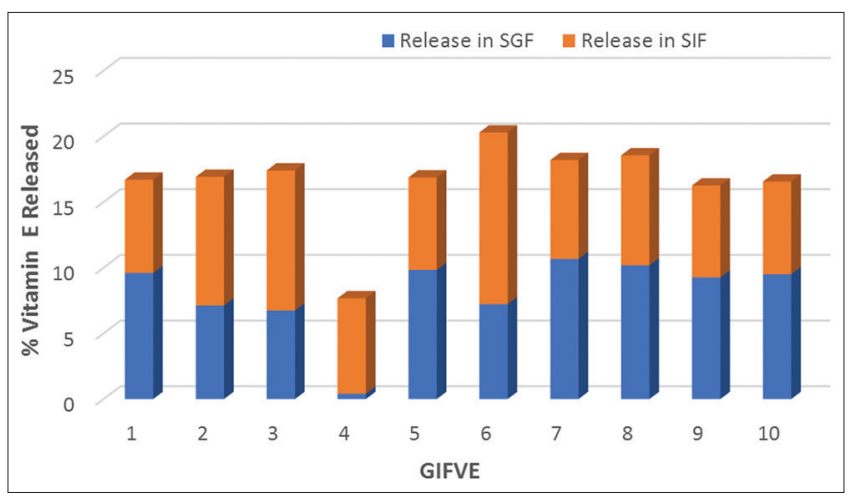

Graph 3: Released profile of Vitamin $\mathrm{E}$ in simulated gastric fluid and simulated intestinal fluid condition

with phosphate. Hence, the appearance of peaks at $1188 \mathrm{~cm}^{-1}, 1249$ $\mathrm{cm}^{-1}$, and $941 \mathrm{~cm}^{-1}$ in the spectra of CGP, which represent stretching $\mathrm{p}=\mathrm{O}$, ester phosphate and stretching $\mathrm{P}-\mathrm{O}-\mathrm{C}$, respectively, confirms the formation of crosslinking.

FT-IR spectra of Vitamin E showed two peaks at $2850-3000 \mathrm{~cm}^{-1}$ which were a stretching of $\mathrm{C}-\mathrm{H}$ group. A peak of aromatic showed slightly higher frequency than aliphatic. A sharp peak observed at $1732 \mathrm{~cm}^{-1}$ in Vitamin E spectra represents a stretching of $\mathrm{C}=\mathrm{O}$ which was probably from the carboxylate group. This was raised from PFAD which also contained a fatty acid. The FT-IR spectra of CGPVE (Fig. 2d) appeared almost similar to the spectra of CGP and Vitamin E. Therefore, it could be reported that Vitamin $\mathrm{E}$ has been doped in CGP matrix and the structure of Vitamin E remained stable after incorporation. Similar spectra have been found by other researchers $[6,20]$.

\section{SEM analysis}

Fig. 1 presents the SEM photograph of GAP, CGP 3, GAP with Vitamin $\mathrm{E}$ and CGPVE 3. As can be seen, there is a difference in surface morphology between the GAP film which has a smooth surface (Fig. 1a) and the hollowed and rough surface of CGP (Fig. 1b). This was due to the occurrence of crosslinking in addition to TMP. The hollowed shape in CGP disappeared after incorporation process. Vitamin E was loaded into the matrix CGP and filled the hollowed shape in CGP rendering the surface smooth and decreasing the hollowed shape size was decreased (Fig. 1c). The CGPVE SEM image was different with the GAP + Vitamin E image which showed a smooth surface without any hollowed shape (Fig. 1d).

\section{Swelling property of CGP}

Our previous research demonstrated that slow, drop by drop addition of TMP could produce CGP with low swelling property and a rough surface and hollowed shape [11]. This result was confirmed by FT-IR spectrum that showed peaks of stretching $\mathrm{P}=0$ at $1188 \mathrm{~cm}^{-1}$, ester phosphate at
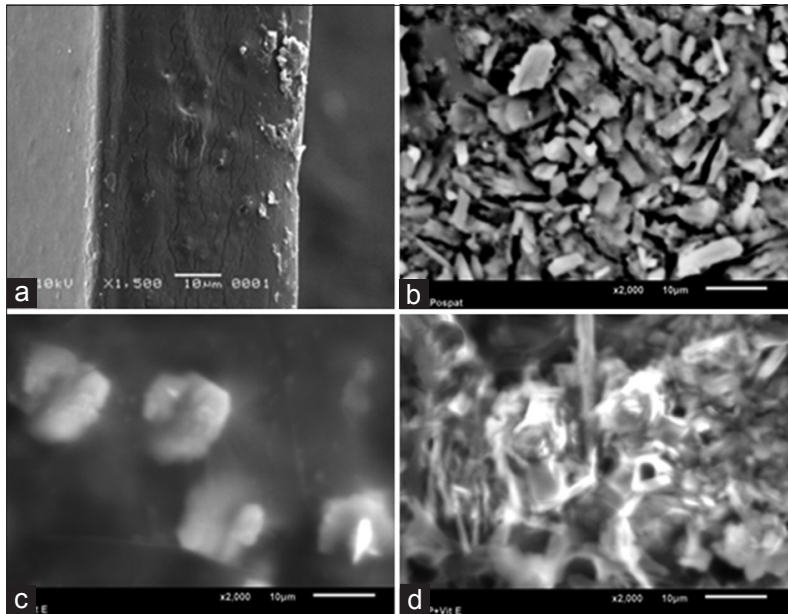

Fig. 1: Scanning electron microscope photographs of cross section galactomannan from Arenga pinnata (GAP) (a), CGP 3 (b), GAP + Vitamin E (c), and CGPVE 3 (d)

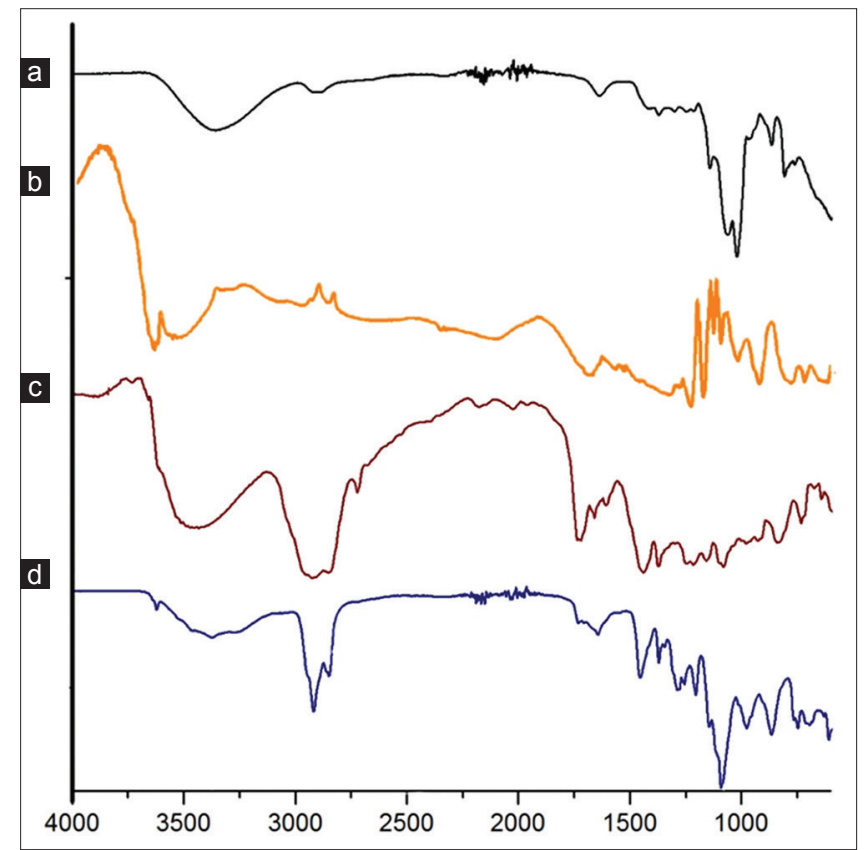

Fig. 2: Fourier transform infrared spectrum of galactomannan from Arenga pinnata (a), CGP (b), Vitamin E (c), and CGPVE (d)

$1249 \mathrm{~cm}^{-1}$, and P-O-C at $941 \mathrm{~cm}^{-1}$. Swelling property study showed that with the increase of the amount of TMF, as shown in CGP 1, CGP 2, CGP 3 and CGP 7, CGP 5 and CGP 10, the swelling property of CGP decreased. Interaction between water with -OH group in GAP decreased as the increment of $-\mathrm{OH}$ group cross-linked with TMF [15]. In reverse, raising the GAP amount could increase the swelling property as shown in Graph 4. The swelling property of CGP was also affected by SGF solution, where the swelling property increased when the $\mathrm{pH}$ of media changed from acid to base, as shown in CGP 1, CGP 2, CGP 3, CGP 6, and CGP 10.

\section{CONCLUSION}

GAP seed has been successfully cross-linked using TMP to produce CGP, which has a lower swelling property and a more hollow shape than GAP. The swelling study of CGP, which was conducted using distillate water, SGF, and SIF, showed that the swelling indexes were similar and decreased with the increase of TMF. The study indicated that it is possible to trap Vitamin E onto CGP matrix. The efficiency of CGP to 


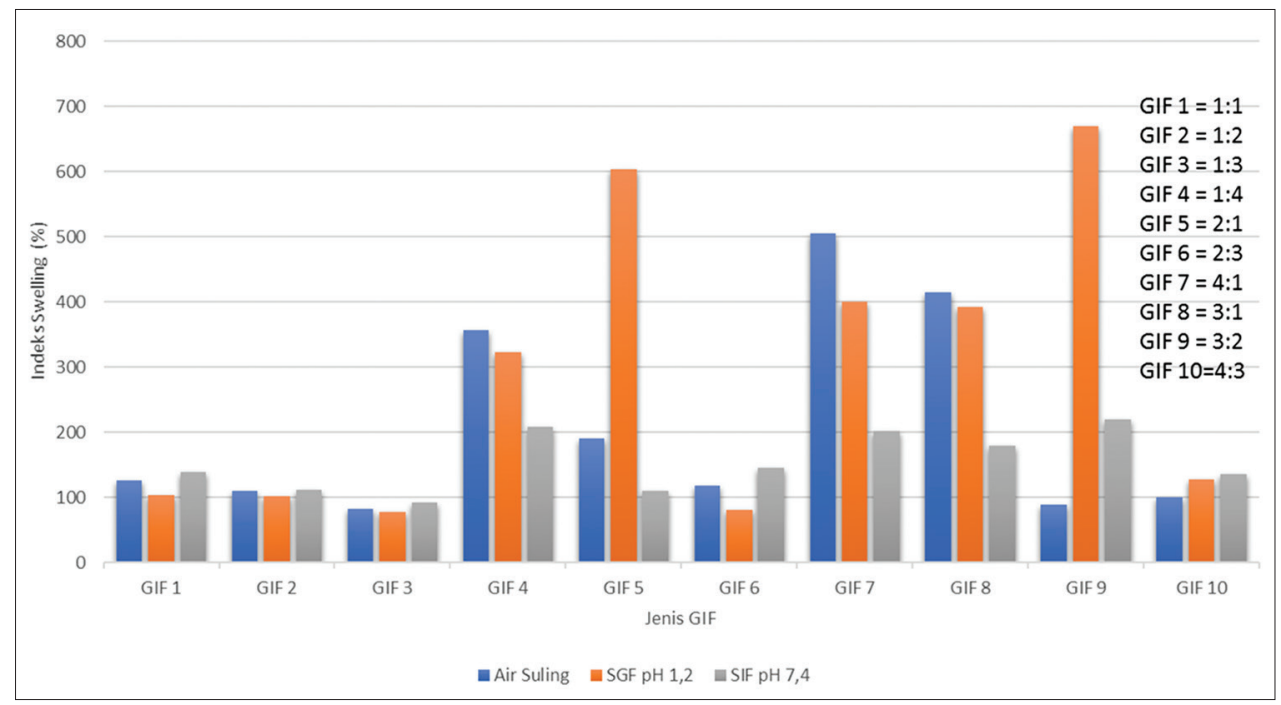

Graph 4: Swelling property of CGP

absorb Vitamin E ranged from $89.66 \%$ to $91.09 \%$. The in vitro releasing study of Vitamin E in SGF and SIF showed that only a small amount of Vitamin E was released. This study demonstrated that CGP can be prepared and is potentially useful for drug delivery to the colon.

\section{ACKNOWLEDGMENT}

This research was supported by the Directorate General of Higher Education -Ministry of Education and Cultural of the Republic Indonesia through grant project number 120/SP2H/PL/Dit.Litabmas/II/2015. The authors also wish to acknowledge the University of Sumatera Utara for their support and help during research.

\section{AUTHORS CONTRIBUTIONS}

Juliati Br. Tarigan (JBT), Djendakita Purba (DP), and Cut Fatimah Zuhra (CFZ) conducted the experiments. JBT wrote and edited the manuscript.

\section{CONFLICT OF INTERESTS}

The authors have no conflict of interest to declare

\section{REFERENCES}

1. Ahmed HH, Aly HF, Ali SA. Potential impact of coq10 and vitamin e against (STZ) induced metabolic deterioration in the Albino rats. Int $\mathrm{J}$ Pharm Pharm Sci 2015;7:176-84

2. Bostick RM, Potter JD, Mckenzie DR, Sellers TA, Kushi LH, Steinmetz KA, et al. Reduced risk of colon cancer with high intake of Vitamin E: The Iowa women's health study. Cancer Res 1993:53:4230-7.

3. Arain MA, Qadeer AA. Systematic review on Vitamin E and prevention of colorectal cancer. Pak J Pharm Sci 2010;23:2.

4. Dasari P, Anandamurali R, Nayak P. Effect of tocotrienol pretreatment on ex vivo superoxide and peroxide handling capacities (SPHC) of rat serum and brain. Int J Pharm Pharm Sci 2017;9:116-22.

5. Luo Y, Zhang B, Whent M, Yu LL, Wang Q. Preparation and characterization of zein/chitosan complex for encapsulation of $\alpha$-tocopherol, and it's in vitro controlled release study. Coll Surf B Biointerfaces 2011;85:145-52

6. Prosapio V, Reverchon E, De Marco I. Incorporation of liposoluble vitamins within PVP microparticles using supercritical antisolvent precipitation. J CO2 Util 2017;19:230-7.

7. Lin SJ, Pascall MA. Incorporation of Vitamin E into chitosan and its effect on the film forming solution (viscosity and drying rate) and the solubility and thermal properties of the dried film. Food Hydrocoll 2014;35:78-84.

8. Sandolo C, Matricardi P, Alhaique F, Coviello T. Effect of temperature and cross-linking density on rheology of chemical cross-linked guar gum at the gel point. Food Hydrocoll 2009;23:210-20.

9. Das A, Wadhwa S, Srivastava A. Cross-linked guar gum hydrogel discs for colon-specific delivery of ibuprofen: Formulation and in vitro evaluation. Drug Deliv 2006;13:139-42.

10. Gliko-Kabir I, Yagen B, Penhasi A, Rubinstein A. Low swelling, crosslinked guar and its potential use as colon-specific drug carrier. Pharm Res 1998;15:1019-25.

11. Tarigan JB, Purba D. Karakterisasi polisakarida galaktomanan kolang kaling (arenga pinnata) terikat silang fosfat. Majalah Polimer Indones 2015;18:1-8.

12. Mogea J, Seibert B, Smits W. Multipurpose palms: The sugar palm (Arenga pinnata (Wurmb) Merr.). Agroforestry Syst 1991;13:111-29.

13. Kooiman P. Structures of the galactomannans from seeds of Annona muricata, Arenga saccharifera, Cocos nucifera, convolvulus tricolor, and Sophora japonica. Carbohydr Res 1971;20:329-37.

14. Tarigan JB. Karakterisasi edible film yang bersifat antioksidan dan antimikroba dari galaktomanan biji aren (Arenga pinnata) yang diinkorporasi dengan minyak atsiri daun kemangi (Ocimum basilicum 1.) [Disertasi]. Medan: Universitas Sumatera Utara; 2014.

15. Gowda DV, Khan MS, Vineela S. Development and evaluation of phosphated cross-linked guar gum microspheres for improved delivery of anticancer drug to colon. Polymer Plastics Technol Eng 2012:51:1395-402

16. Somchue W, Sermsri W, Shiowatana J, Siripinyanond A. Encapsulation of $\alpha$-tocopherol in protein-based delivery particles. Food Res Int 2009:42:909-14.

17. Liang L, Line VL, Remondetto GE, Subirade M. In vitro release of $\alpha$-tocopherol from emulsion-loaded $\beta$-lactoglobulin gels. Int Dairy $\mathrm{J}$ 2010;20:176-81.

18. Cerqueira MA, Lima AL, Souza BW, Teixeira JA, Moreira RA, Vicente AA. Functional polysaccharides as edible coatings for cheese. J Agric Food Chem 2009;57:1456-62.

19. Üner M, Altınkurt T. Evaluation of honey locust (Gleditsia triacanthos Linn.) gum as sustaining material in tablet dosage forms. Il Farmaco 2004;59:567-73.

20. Renò F, Aina V, Gatti S, Cannas M. Effect of Vitamin E addition to poly (d, 1)-lactic acid on surface properties and osteoblast behaviour. Biomaterials 2005;26:5594-9. 